\title{
Reproducibility of the Quantification of Reversible Wall Interactions in VOC Sampling Lines
}

\author{
Guido Sassi *, Bilal Alam Khan and Maricarmen Lecuna (D) \\ Department of Applied Science and Technology, Politecnico di Torino, 10129 Torino, Italy; \\ bilal.khan@polito.it (B.A.K.); maricarmen.lecuna@polito.it (M.L.) \\ * Correspondence: guido.sassi@polito.it
}

Citation: Sassi, G.; Khan, B.A.; Lecuna, M. Reproducibility of the Quantification of Reversible Wall Interactions in VOC Sampling Lines. Atmosphere 2021, 12, 280. https:// doi.org/10.3390/atmos12020280

Academic Editor: Stéphane Le Calvé

Received: 27 January 2021

Accepted: 12 February 2021

Published: 20 February 2021

Publisher's Note: MDPI stays neutral with regard to jurisdictional claims in published maps and institutional affiliations.

Copyright: (c) 2021 by the authors. Licensee MDPI, Basel, Switzerland. This article is an open access article distributed under the terms and conditions of the Creative Commons Attribution (CC BY) license (https:// creativecommons.org/licenses/by/ $4.0 /)$.

\begin{abstract}
Volatile Organic Compounds (VOCs) are widely measured at ppb and ppt level in many contexts, from therapeutic drug control in respiratory diseases to monitoring of climate change and indoor air quality. The need for accuracy is a common denominator in all these fields. The interactions between gas mixtures and solid surfaces in sampling lines and instruments play an important role in calculating the total uncertainty of the amount of VOC. The amount of substances in the gas mixture is affected by its reversible and irreversible interactions with the sampling line. The main aim of this paper is to propose and discuss a method to quantify the amount of substance segregated by reversible interactions on sampling lines. To validate the proposed method, the areic amount of a VOC (Acetone) is measured for a commercial test pipe (Sulfinert ${ }^{\circledR}$ ) as the amount of substance per unit area of the internal surface of the test pipe segregated from the flowing gas mixture. Stainless steel coated by Sulfinert ${ }^{\circledR}$ was chosen as a test material because of its wide use and its limited irreversible and permeation effects. A certified gas mixture of Acetone in air with a nominal mole fraction of $10 \mu \mathrm{mol} \mathrm{mol}{ }^{-1}$ was used for validation. Broad temperature control was used and the sensibility of the method to the temperature and the pressure has been evaluated to correct the bias due to physical condition. The sensitivity to the residence time and the Reynolds number of the gas flow has been evaluated to verify the reaching of equilibrium and the limits of the applicability of the method. The areic amount of Acetone at equilibrium on Sulfinert ${ }^{\circledR}$ coated pipe was measured as $40 \mathrm{nmol} \mathrm{m}{ }^{-2}$, and an equilibrium constant value of around $0.2 \mathrm{~m}$ was calculated as the ratio between the superficial amount segregated on the wall and the amount concentration of Acetone in the mixture, both at the equilibrium. The observed reproducibility was better than $2.5 \%$. This method is aimed to investigate VOC losses due to interactions for many VOC/material systems at a lower amount of substance levels.
\end{abstract}

Keywords: VOC measurements; surface interaction; gas sampling; acetone; Sulfinert ${ }^{\circledR}$; equilibrium; uncertainty

\section{Introduction}

The measurements of volatile organic compounds (VOCs) at trace level have a major role in atmospheric chemistry, health, ultra-clean industrial processes, indoor air quality, and metrology [1,2]. In all these applications, measurements of VOCs amount of substance require a challenging target accuracy at the level of pmol mol${ }^{-1}$ (ppt) and nmol mol $\mathrm{mol}^{-1}$ (ppb) [1]. VOCs' monitoring within 1-1000 ppb range is required for the atmosphere and indoor air quality at an uncertainty of $5 \%$ for different VOCs and $3 \%$ for different fluorinate volatile compounds [3-5]. VOCs are ozone precursors that affect ozone production in the presence of NOx and light; these are harmful pollutants at a lower altitude [6]. VOCs having $\mathrm{C}=\mathrm{C}$ double bonds are more reactive, which upon oxidation produces a large variety of particle-phase compounds that are more hazardous than the original one [7]. Indoor VOC concentrations are higher than outdoor ones [8,9], and human exposure to these VOCs can have short- and long-term adverse effects on their health. Many VOCs are also 
considered to be Airborne Molecular Contaminants (AMCs), which can be a threat to the yield of ultra-sensitive manufacturing processes such as semiconductor, nanotechnology, and photovoltaics that raises the need for accuracy in measurements at ppb level [10-12]. A good estimation of uncertainty in measurements of emitted VOCs from different parts of the human body is essential due to its role as a biomarker that is used to detect different diseases including lung cancer [13-17].

VOCs monitoring, regardless of the application, requires the use of pipes, fittings, liners, cylinders, joints, pressure regulators, environmental chambers, generation devices, and measurement instruments, all built using solid materials of different nature. In all these applications, the gas-wall interactions affect the mole fraction of VOCs [18-26]. Sampling pipes that convey the air from the atmosphere to the detectors can potentially disturb the measurement of the amount of the analyte segregating on or releasing from the wall surfaces, i.e., these interactions challenge the accuracy of the measurement [26]. The gas mixtures interact by adsorption, desorption, and reactions with the available surfaces, both at the wall or, by permeation, inside of it [27].

The adsorption and desorption of gases over the surfaces are the sum of collective phenomena that occur in series and/or parallel [28]. The gas-wall interactions cause reversible and irreversible losses that depend on the different parameters such as contact time, contact area, and thermodynamic conditions [29]. The characteristics of the analyte, e.g., polarities and molecular mass, are crucial in determining the nature and intensity of interactions [30]. Losses due to interactions are significant for oxygenated VOCs (OxyVOCs) and Terpenes because of their high affinity with the wall that leads to adsorption and reactions $[5,30,31]$. The lower the Oxy-VOC mole fraction is the more important it is to use suitable materials to minimize losses on wall surfaces.

Interactions with polymeric materials like PFA (Perfluoroalkoxy alkanes) and FEP (fluorinated ethylene propylene) are very small; polymeric materials are recommended for sampling lines [26,32-34]. However, polymers can cause undesirable effects because of their permeability for gases while glass and metals because of their affinity for surface adsorption and reactions $[30,35]$.

Where reaction products are formed by gas to wall interactions, identification of substances can be difficult [36]. Interactions can affect the stability and accuracy of the standard gas mixture at trace level for both static and dynamic preparations [5,18,19,31,37-39]. The losses due to interactions in cylinders had been widely investigated in References [40-46]. A method for the estimation of losses in cylinders has recently been proposed [37].

The impact of the gas-wall interactions on VOCs' measurements in sampling lines has been recently under study [1,5,20,22,31,47-50], but results are still limited. Teflon, polymeric material, coated and uncoated steel, glass, and aluminum have been considered. A comparison of interactions of gas mixtures and different materials was based on the absorptive partitioning effects on delays; Teflon and PFA proved to be the best at a level of $100 \mu \mathrm{g} \mathrm{m}^{-3}[20,48]$. Quantification of gas-wall partitioning was proposed on Teflon chambers [22]. Chambers has a reduced control of local fluid dynamic conditions and subjected to buoyancy effects [22].

Quantification of losses aimed to correct a bias in VOC measurement has not yet been proposed, to this aim, a correction has to be quantified with a proper target accuracy. Simplified conservative quantification of the losses due to gas-wall interactions in the sampling lines has been proposed, it is based on the value of an equilibrium amount of VOC adsorbed on the pipe wall [1]. A quantification of equilibrium amount segregated on the material surface is available from theoretical insight and models for few types of wall materials [30]. Equilibrium between gas mixtures and pipe walls is expected to be at a constant ratio between potentials on the two phases expressed as an amount per unit volume of mixture and amount per unit active surface of pipe wall [30]. Experimental methods have been proposed in research projects [5,31], the preliminary results showed a very large uncertainty in theoretical previsions and a low reproducibility in experimental data [31]. The purpose is to investigate interaction at a very low level using a PTR-MS as 
detectors [5], but the risk of working at a low level is to have instability of sources that do not allow to have reliable data on the material properties. This paper is aimed to fix a starting point of a quantitative method for the measure of reversible interactions before applying the method to a low amount of substance.

The novelty of the paper is the proposal of a quantitative method for reproducible measurement of interactions in sampling lines to offer reliable data to calculate the biases affecting VOC measurements. This paper describes the method in detail and discusses the reproducibility of an application to measure the reversible interactions between a VOC (Acetone) gas mixture and a commercial pipe, which is typically used for sampling when interactions can be critical (Sulfinert ${ }^{\circledR}$ ). An experimental set-up has been designed, in which a mixture containing a single VOC was flushed inside a clean test pipe. A fast response detector was used to retrieve the signal of VOC concentration. The amount of VOC segregated from the mixture was calculated from the depletion of the signal. The amount of VOC segregated per unit area $\left(C_{A, e}\right)$ was considered to calculate an equilibrium constant $\left(K_{e}\right)$ of VOC adsorption on the internal surface of the test pipe. The acetone $\left(\mathrm{CH}_{3}-\mathrm{CO}-\mathrm{CH}_{3}\right)$ mixture in air at the ppm level with certified uncertainty is used for the experiments due to the stability of acetone, its high response on the detector, and its importance in applications $[3,5,31,51]$. The chosen test material was Sulfinert ${ }^{\circledR}$ because the stainless steel pipe wall limits the permeation rate and the silicon inert coating limits gas-wall interactions, the irreversible ones in particular. Materials and operating conditions were selected to limit the risk of instability and low reproducibility due to the source of mixtures, to the detection system, and to the mutual effects of other interaction ways (irreversible interactions and permeation).

The correction of biases in measurements was discussed. The paper reports sensitivities of the areic adsorbed amount to the contact time between gas mixture and pipe, and to the fluid dynamic conditions. The sensitivity tests were performed on a wide range of gas flow rates and with different lengths of test pipe in order to verify if transport phenomena are affecting the measurement.

\section{Materials and Methods}

\subsection{Experimental Set-Up}

An experimental set-up for the quantification of the gas-wall interaction has been developed. The set-up allows to switch the feed to a detector between two different sources of gas, i.e., Zero gas (VOC free) or VOC Mixture, directly or through a test pipe. The schematic drawing is shown in Figure 1. The Zero gas obtained from a commercial dry air cylinder (A) is considered with a negligible amount of hydrocarbons. The VOC Mixture source is a cylinder containing a certified reference mixture of Acetone in air (M). Each feed has a controlled flowrate, sources $A$ and $M$ are connected to sonic nozzles $\left(S_{N 1}\right.$ and $\left.S_{N 2}\right)$ and regulated by the pressure-reducing valves $\left(V_{R 1}\right.$ and $\left.V_{R 2}\right)$ to deliver a stable flowrate for each experiment. Two identical 4-way crossover valves with a limited contact surface and dead volume have been chosen to select between feeds $\mathrm{A}$ and $\mathrm{M}\left(V_{s 1}\right)$ and between bypass and test pipe $\left(V_{s 2}\right)$. The valve $V_{s 1}$ switches the feed $\mathrm{A}$ or $\mathrm{M}$ stream between a vent line to measure the mass flow rate $\left(q_{V 0} I\right)$ and a detector line (flame ionization detector (FID)). The valve $V_{s 2}$ has 2 identical internal ducts, one of them acts as a bypass, the second one is accounted as a part of the test pipe. The Flame ionization detector (FID) of a gas chromatograph (Bruker GC-450) is used for the detection of VOC in the feed after the test pipe/bypass. The mass flow rate is measured by two $100 \mathrm{SmL} / \mathrm{min}$ Bronkhorst mass flow meters $\left(q_{V 0} I\right)$ operating in parallel to reach a total full scale of $200 \mathrm{SmL} / \mathrm{min}$. The test pipes have been insulated by polystyrene sheets to improve temperature stability. Test runs with different setpoints for the room temperature have been performed, in the range from $17^{\circ} \mathrm{C}$ to $30^{\circ} \mathrm{C}$. 


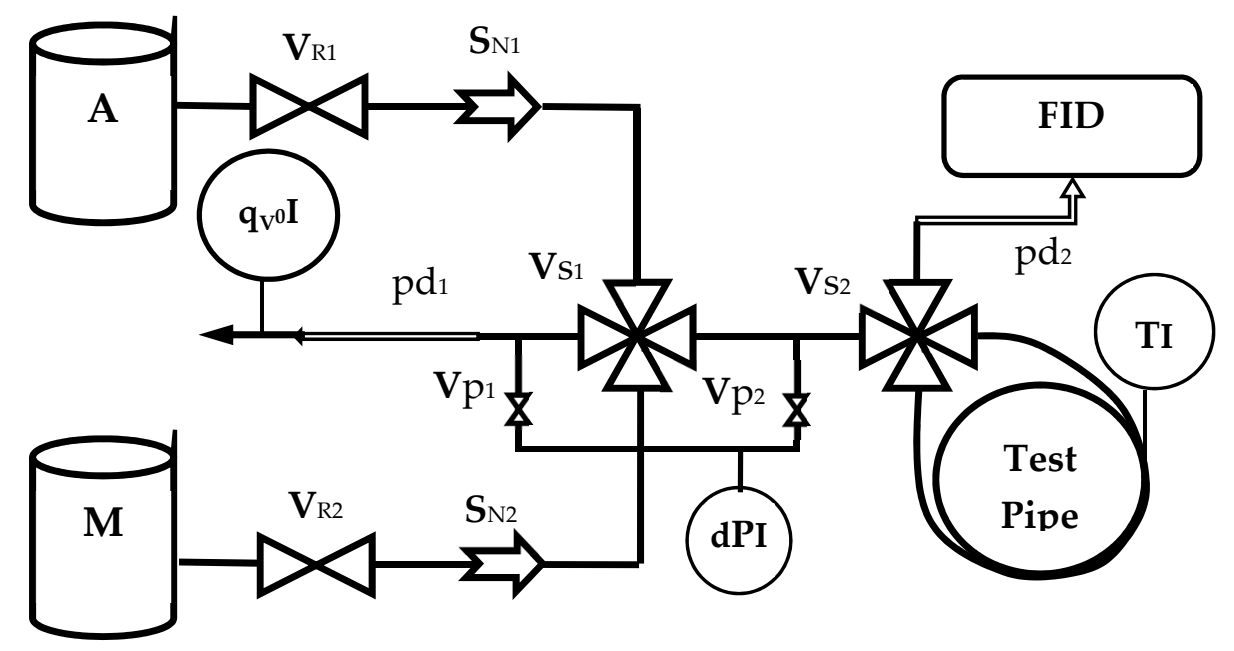

Figure 1. Scheme of the experimental setup. $\left(\mathrm{V}_{\mathrm{R}}\right.$ : Pressure reducing valve; $\mathrm{V}_{\mathrm{s}}$ : 4-way Switch valves; $\mathrm{V}_{\mathrm{p}}$ : interception valve; FID: Flame Ionization Detector; SN: Sonic Nozzle; pd: Capillary pipe; $q_{V 0} I$ : Mass Flowmeter; A: Zero Air Cylinder; M: VOC Mixture Cylinder; dPI: Pressure Indicator; TI: Temperature Indicator.).

Time variability of $\pm 2{ }^{\circ} \mathrm{C}$ and spatial variability of $\pm 2{ }^{\circ} \mathrm{C}$ have been observed in the test pipe external wall. The temperature of the test pipe is measured with calibrated temperature sensors Pt-100 (TI) on the external surface of the test pipe during the experiments in different positions along the test pipe.

Pressure spikes occur when $V_{s 1}$ is switched, they are limited by keeping the same pressure drop on the vent and the FID line by additional pressure drops in capillary pipes $\mathrm{pd}_{1}$ and $\mathrm{pd}_{2}$. The pressure drop was measured by a Yokogawa MT-110 (dPI) as the differential pressure from the room atmospheric pressure. Valves $V_{p 1}$ and $V_{p 2}$ allow measuring the pressure drop on the vent line and the FID line, respectively.

The system is checked periodically for leaks using the procedure described in Reference [1]. Leak tests are performed after FID signal stabilization at the initial switch-on (at least two hours). The residence time of the gas stream in the test pipe $\left(\tau_{r}, \mathrm{~min}\right)$ is estimated as the ratio between the internal test pipe volume $\left(V_{t}, \mathrm{~mL}\right)$ and the gas volumetric flow rate $\left(q_{V, g}, \mathrm{~mL} \mathrm{~min}^{-1}\right)$ :

$$
\tau_{r}=\frac{V_{t}}{q_{V, g}}=\frac{\frac{\pi D^{2} L}{4}}{q_{V^{0}, g} \frac{P^{0}}{P} \frac{T}{T^{0}}}
$$

where $D(\mathrm{~cm})$ and $L(\mathrm{~cm})$ are the internal diameter and length of the test pipe, respectively; $T(\mathrm{~K})$ and $P(\mathrm{kPa})$ are average temperature and pressure in the test pipe, respectively; $d P$ $(\mathrm{kPa})$ is the pressure drop on FID line; superscript 0 accounts for standard condition $\left(0{ }^{\circ} \mathrm{C}\right.$, $1 \mathrm{bar}) ; q_{V 0, g}\left(\mathrm{SmL} \mathrm{min}^{-1}\right)$ is the mass flow rate expressed as volumetric flow rate at standard condition measured by the mass flow meter. The average pressure in the pipe is calculated as the sum of pressure drop and atmospheric pressure. Pressure drop was calculated as the mean of pressure drops with and without test pipe, and atmospheric pressure was calculated as average atmospheric pressure over the experiment (data retrieved from Reference [52]). Four different configurations have been selected for the experimental quantification of the gas-wall interaction, two of them are reported in Figure 2. 


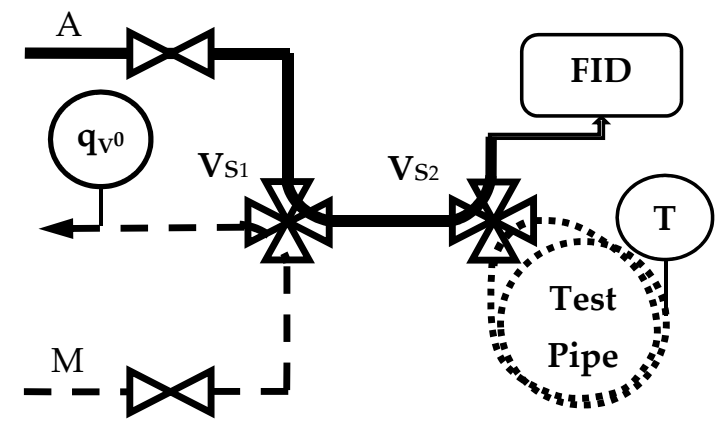

Configuration A: Zero Air flowing in bypass, VOC Mixture flowing to vent

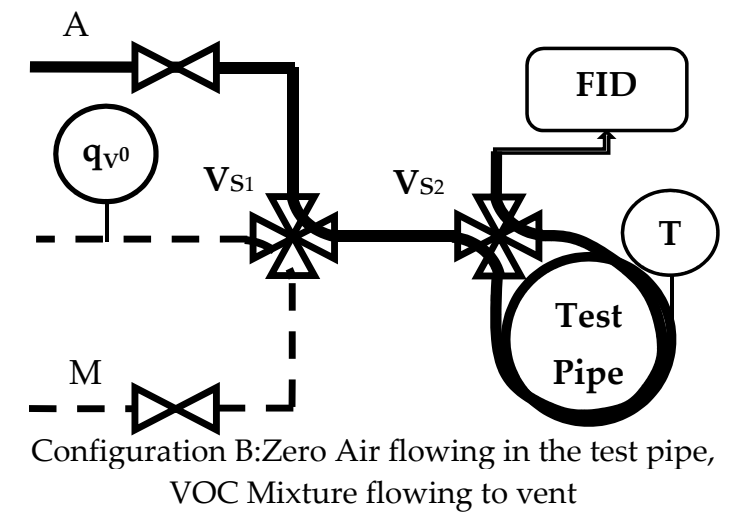

Figure 2. Device connections for monitoring the VOC Mixture and Zero Air in bypass and test pipe. The solid line represents the Zero Air and the dashed line shows the VOC Mixture the dotted line is without flow.

- Configuration A: the detector receives the Zero Air flowing through the bypass while the VOC Mixture is sent to the vent (Ref. Figure 2); gas is entrapped in the test pipe.

- Configuration B: the detector receives the Zero Air flowing through the test pipe while the VOC Mixture is sent to the vent (Ref. Figure 2).

- Configuration C: the detector receives the VOC Mixture flowing through the bypass, while Zero Air is sent to the vent; Zero Air is entrapped in the test pipe.

- Configuration D: the detector receives the VOC Mixtures flowing through the test pipe while Zero Air is sent to the vent.

To switch from Configuration A to C and from B to D and vice versa, valve $V_{s 1}$ is turned by $90^{\circ}$; to switch from Configuration $A$ to $B$ and from $C$ to $D$ and vice versa, valve $V_{s 2}$ is turned by $90^{\circ}$.

\subsection{Materials}

Tests were performed on commercial pipes with $1 / 8^{\prime \prime}$ nominal diameter, internal diameter was measured by weighing pipes empty and filled by water on $1 \mathrm{~m}$ pipe length with $0.1 \%$ uncertainty. Sulfinert ${ }^{\circledR}$ coated stainless steel with pipe lengths of $26 \pm 0.13 \mathrm{~m}$ and $8.5 \pm 0.045 \mathrm{~m}$ has been tested. Two samples, $8.5 \mathrm{~m}$ long, were cut from a Sulfinert ${ }^{\circledR}$ $26 \mathrm{~m}$ pipe. Acetone was chosen as VOC because of its high response on FID and its chemical stability [51], of its very low toxicity, and of its importance in applications [3,5,31]. Acetone at a nominal $10 \mu \mathrm{mol} \mathrm{mol}^{-1}$ was supplied as a VOC mixture in air from a gas cylinder. Experiments were performed from two cylinders of the same nominal mole fraction $\left(\chi=10 \pm 0.3 \mu \mathrm{mol} \mathrm{mol}^{-1}\right.$, SIAD certified mixture $\chi=9.78 \pm 0.38 \mu \mathrm{mol} \mathrm{mol}^{-1}$ and $\chi=9.86 \pm 0.35 \mu \mathrm{mol} \mathrm{mol}{ }^{-1}$ Acetone in air.) and the results were compared on tests; the effect on repeatability was negligible. $\mu \mathrm{mol} \mathrm{mol}^{-1}$ level was selected to assure higher stability of the acetone source supplied to the device for cylinder, pressure reducer, and line.

\section{Methodology}

\subsection{Measurand Equation: Amount of VOC Adsorbed Per Unit Area of Wall at Equilibrium}

The definition of the measurand is "the amount of VOC adsorbed per unit area of wall at equilibrium", i.e., the areic amount of $\operatorname{VOC}\left(C_{A, e}\right)$ in $\mathrm{mol} \mathrm{m}^{-2}$. It can be calculated by the information about the mixture entering (subscript in) and leaving (subscript out) the test pipe through a simple mass balance for the conservation of VOC, i.e., VOC changes state from free molecule to molecule adsorbed on the wall (VOC (gas) $\rightarrow \mathrm{VOC}$ (wall)), in a cylinder, i.e., the test pipe. The mass balance (in moles) can be written as: "the amount of VOC entering the test pipe per unit time $\left(q_{n V O C, i n}, \mathrm{~mol} \mathrm{~min}^{-1}\right)$ leaves the test pipe as the amount of VOC exiting the test pipe per unit time $\left(q_{n V O C, \text { out }}, \mathrm{mol} \mathrm{min}^{-1}\right)$ or remains inside 
the test pipe as the amount of VOC adsorbed on the wall $\left(d n_{V O C}\right.$, wall, mol) in the unit time" or, in a mathematical way:

$$
q_{n_{V O C}, \text { in }}=q_{n_{V O C, \text { out }}}(t)+\frac{d n_{V O C, \text { wall }}(t)}{d t}
$$

The measurand $\left(C_{A, e}, \mathrm{~mol} \mathrm{~m}^{-2}\right)$ can be calculated from the integral by parts of equation (2) as the integral on time of the difference between the amount entering $\left(q_{n V O C, \text { in }}\right.$, mol $\left.\mathrm{min}^{-1}\right)$ and leaving $\left(q_{n V O C, \text { out }}, \mathrm{mol} \mathrm{min}^{-1}\right)$ the test pipe per unit time. The time interval is from clean pipe $\left(t_{0}\right)$ to saturated pipe $\left(t_{\infty}\right)$. The amount is referred to the unit area A of the wall to calculate the areic amount of substance at equilibrium:

$$
\begin{aligned}
& C_{A, e}= \frac{n_{\infty}}{A}=\int_{0}^{n_{\infty}} \frac{d n_{V O C, \text { wall }}(t)}{A}=\int_{t_{0}}^{t_{\infty}} \frac{q_{n_{V O C} \text {,in }}-q_{V O C, \text { out }}(t)}{A} d t \\
& C_{A, e}=\frac{q_{n_{V O C, \text { in }}}}{A} \int_{t_{0}}^{t_{\infty}}\left(1-\frac{q_{n_{V O C \text {, out }}(t)}}{q_{n_{V O C} \text {,in }}}\right) d t
\end{aligned}
$$

The areic amount of VOC at the equilibrium is thus the sum $\left(n_{\infty}\right)$ of all the aliquots of VOC adsorbed on the wall $\left(n_{V O C, \text { wall }}\right)$ moment by moment from the beginning of the exposure till the equilibrium, theoretically till infinitive time $\left(t_{\infty}\right)$.

The amount of VOC entering the test pipe $\left(q_{n V O C, \text { in }}, \mathrm{mol} \mathrm{min}^{-1}\right)$ is independent of time and it can be calculated as:

$$
q_{n_{V O C, \text { in }}}=q_{V_{g}, \text { in }} C_{V, \text { in }}=q_{V_{g}^{0}} \chi_{M i x} \frac{P^{0}}{R T^{0}}
$$

where $C_{V, \text { in }}\left(\mathrm{mol} \mathrm{mL}^{-1}\right)$ is the mole concentration, i.e., amount concentration, of VOC and $\mathrm{q}_{\mathrm{Vg}, \mathrm{in}}\left(\mathrm{mL} \mathrm{min}^{-1}\right)$ is the total volumetric gas flow rate feeding the test pipe; $\chi_{\text {Mix }}$ $\left(\mathrm{mol} \mathrm{mol}^{-1}\right)$ is the mole fraction, i.e., the amount fraction, of VOC in the mixture and $q_{V_{g}^{0}}\left(\mathrm{SmL} \mathrm{min}{ }^{-1}\right)$ is the total standard volumetric gas flow rate $\left(0^{\circ} \mathrm{C}, 1 \mathrm{bar}\right)$, its value is practically uniform along the test pipe, i.e., the amount of VOC segregated at the wall is negligible with respect to the total amount flow rate; $T^{0}(\mathrm{~K})$ and $P^{0}(\mathrm{kPa})$ are the temperature and pressure at standard conditions $\left(0^{\circ} \mathrm{C}, 1 \mathrm{bar}\right)$ and $R\left(\mathrm{~kJ} \mathrm{~K}^{-1} \mathrm{~mol}^{-1}\right)$ is the gas constant.

While the ratio between the amount flow rate of VOC entering and leaving the test pipe can be expressed as the dimensionless mole fraction of VOC $(\zeta)$ as long as the total mole flow rate accounted as standard volumetric flow rate $\left(q_{V^{0}}\right)$ is uniform along the test pipe (in other words as long as the amount of VOC adsorbed is negligible with respect to the total amount of gas). A baseline signal of FID is related to several effects, and to account for all the possible effects, clean air has been flushed in the system [51]. FID signal shift from the baseline is proportional to the total amount of carbon burned in the flame in the unit time, and the response factor is proper of each substance mainly based on the molecular formula [51]. This quantity can be calculated from the signal as:

$$
\frac{q_{n_{V O C}, \text { out }}(t)}{q_{n_{V O C}, \text { in }}}=\frac{\chi_{\text {out }}}{\chi_{\text {Mix }}}=\zeta(t)=\frac{S(t)-S_{\text {Air }}}{S_{\text {Mix }}-S_{\text {Air }}}
$$

where $S(\mathrm{mV}$, in the case of FID) is the signal from the detector when flowing the Zero Air $\left(S_{\text {Air }}\right)$, the VOC Mixture from bypass $\left(S_{M i x}\right)$, the gas coming from the test pipe at time $t$ $(S(t))$. Equation (6) is the final shape of the measurand equation, where $\zeta$ is calculated from Equation (5).

$$
C_{A, e}=\frac{P^{0} q_{V^{0}, g} \chi_{M i x}}{A R T^{0}} \int_{t_{0}}^{t_{\infty}}(1-\zeta(t)) d t
$$

During the adsorption (from $t_{0}$ to $t_{\infty}$ ), the ideal plug flow $(\zeta=1)$ is shifted to the actual dimensionless mole fraction $(\zeta(t))$ because of adsorption, the integral of the difference $(1-\zeta(t))$ between the ideal dimensionless mole fraction, and the actual one is the amount of adsorption effect in the test pipe. 


\subsection{Measurement Procedure}

The procedure is aimed to get the measurand realization. The test pipe must be cleaned by flushing zero gas (Air) and then exposed to the VOC Mixture over a time interval to measure the VOC uptake. After saturation, the pipe is exposed to the Air over a time interval to measure the VOC release. For cleaning the pipe, configuration B is set till the signal is stabilized at $S_{\text {Air }}$. After cleaning by Air, the test pipe is isolated from the device and the device is exposed to the VOC Mixture (Switch to configuration A first, and then configuration C) till the signal is stabilized at $S_{\text {Mix }}$ and the device is saturated. Once the stability is reached, the test pipe is exposed to VOC Mixture (Switch to configuration D) till the signal is stabilized again at $S_{M i x}$. The procedure results in signal shape, a typical shape is reported in the central part of Figure 3 for 6 repeated measurements.

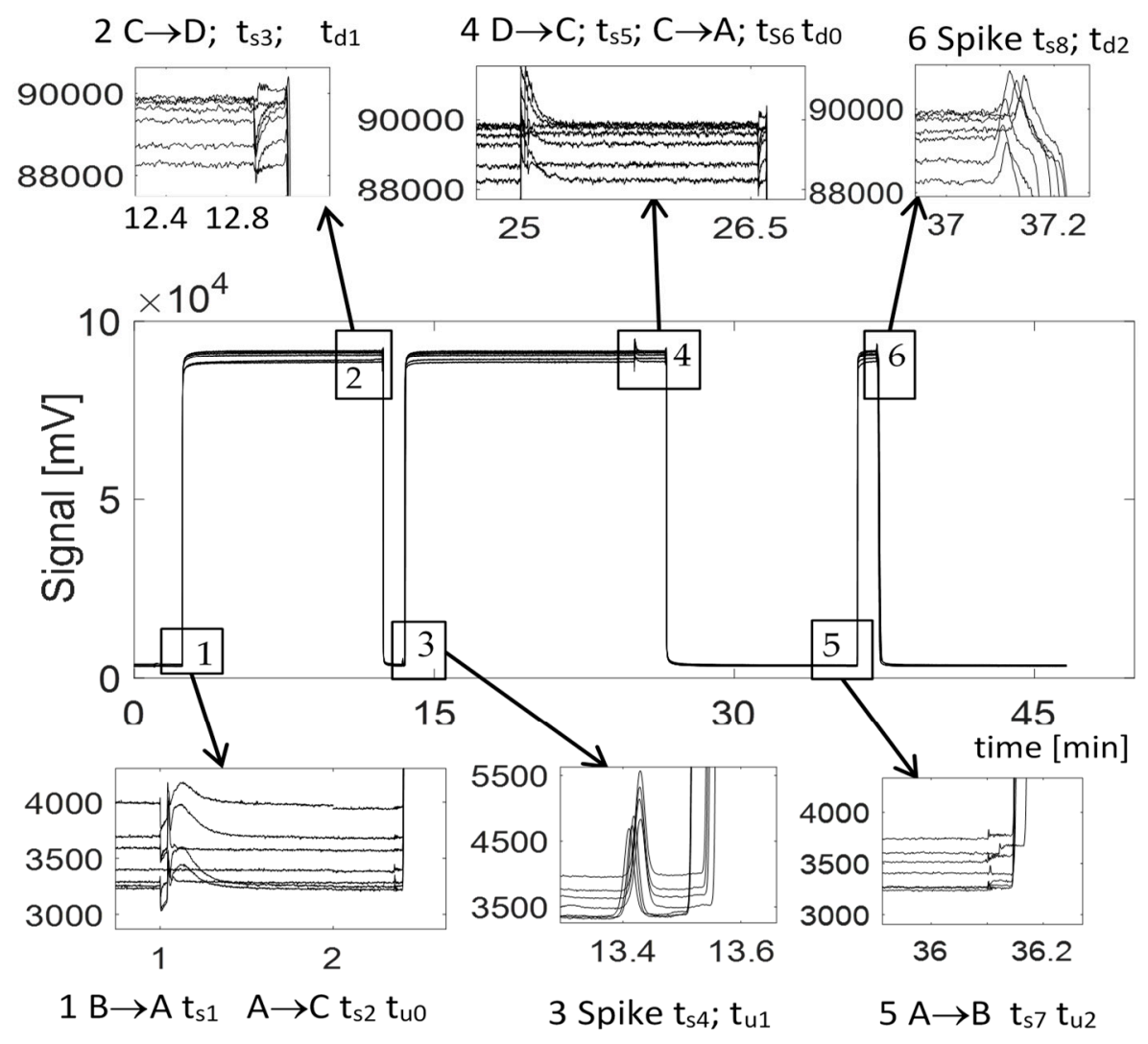

Figure 3. FID signal during measurement, spike times of events from Table 2 are reported at the boxes which zoom on the signal. Experimental raw data for the sample Sulfinert A at $100 \mathrm{SmL} / \mathrm{min}$, 6 repeated experiments.

The procedure is reported in Table 1 as the sequence of configurations and switches performed during a single measurement. The procedure is completed with the desorption reaching again the initial conditions after cleaning. The effects reported in Table 1 are deviations from the theoretical signal behavior. Spikes in the signal were observed in correspondence to switches and other occurrences. Delays were observed for the appearance and disappearance of VOC in FID. Figure 3 reports a typical pattern of the signal along a run, the different curves give an idea or repeatability of the experiment. Boxes enlarge the scales of the signal to put in evidence deviations. Spikes identify the time of events from a physical direct measurement. Table 2 reports the time correspondence and reference to box numbers in Figure 3. 
Table 1. Sequence of configurations on measurement.

\begin{tabular}{|c|c|c|c|c|c|c|}
\hline \multirow{2}{*}{$\begin{array}{c}\text { Switch } \\
\text { B }\end{array}$} & \multirow[t]{2}{*}{ Valve } & \multirow{2}{*}{$\begin{array}{l}\mathbf{S}_{\infty} \\
S_{\text {Air }}\end{array}$} & \multicolumn{2}{|c|}{ Test Pipe } & \multirow{2}{*}{ Gas } & \multirow{2}{*}{$\begin{array}{c}\text { Operation and Effects } \\
\text { Cleaning device and test pipe till Flat signal }\end{array}$} \\
\hline & & & In & Clean & & \\
\hline $\mathrm{B} \rightarrow \mathrm{A}$ & $V_{s 2}$ & $S_{\text {Air }}$ & Off & Clean & Zero & Spike $\left(t_{s 1}\right)$ at switch \\
\hline $\mathrm{A} \rightarrow \mathrm{C}$ & $V_{s 1}$ & $S_{\text {Mix }}$ & Off & Clean & VOC & Spike $\left(t_{s 2}\right)$ at switch, $t_{u 0}$, Saturating device \\
\hline$C \rightarrow D$ & $V_{s 2}$ & $S_{\text {Mix }}$ & In & Sat. & VOC & $\begin{array}{l}\text { Spike }\left(t_{s 3}\right) \text { at switch } \\
\text { Signal depletion }\left(t_{d 1}\right) \text { after device residence time } \\
\text { Spike }\left(t_{s 4}\right) \text { after test pipe residence times } t_{u 1}\end{array}$ \\
\hline $\mathrm{D} \rightarrow \mathrm{C}$ & $V_{s 2}$ & $S_{\text {Mix }}$ & Off & Sat. & VOC & Spike $\left(t_{s 5}\right)$ at switch, Cleaning device \\
\hline $\mathrm{C} \rightarrow \mathrm{A}$ & $V_{s 1}$ & $S_{\text {Air }}$ & Off & Sat. & Zero & Spike $\left(t_{s 6}\right)$ at switch $t_{d 0}$ \\
\hline $\mathrm{A} \rightarrow \mathrm{B}$ & $V_{s 2}$ & $S_{\text {Air }}$ & In & Clean & Zero & $\begin{array}{l}\text { Spike }\left(t_{s 7}\right) \text { at switch } \\
\text { Signal increase }\left(t_{u 2}\right) \text { after device residence time } \\
\text { Spike }\left(t_{s 8}\right) \text { after test pipe residence times, } t_{d 1}\end{array}$ \\
\hline
\end{tabular}

Table 2. Correspondence of signal times with residence/contact times, box refers to Figure 3.

\begin{tabular}{|c|c|c|c|}
\hline Time & Box & Event & Characteristic Time \\
\hline Spike $t_{s 1}$ & 1 & $\mathrm{~B} \rightarrow \mathrm{A}$ Switch & \\
\hline Spike $t_{s 2}$ & 1 & $\mathrm{~A} \rightarrow \mathrm{C}$ Switch & \\
\hline$t_{u 0}$ & 1 & VOC Mixture reaches FID & $\begin{array}{c}t_{u 0}-t_{s 2} \text { Residence time from } V_{s 1} \text { to detector } \\
\text { no test pipe }\end{array}$ \\
\hline Spike $t_{s 3}$ & 2 & $\mathrm{C} \rightarrow \mathrm{D}$ Switch & \\
\hline$t_{d 1}$ & 2 & Air entrapped reaches FID & $t_{d 1}-t_{s 3}$ Residence time from $V_{s 2}$ to detector \\
\hline Spike $t_{s 4}$ & 3 & $\begin{array}{l}\text { VOC Mixture reaches FID } \\
\text { without VOC (all adsorbed on wall) }\end{array}$ & $\tau_{r}=t_{s 4}-t_{d 1}$ Residence time in test pipe \\
\hline$t_{u 1}$ & 3 & VOC starts to overpass pipe & Delay of VOC appearance \\
\hline Spike $t_{s 5}$ & 4 & $\mathrm{D} \rightarrow \mathrm{C}$ Switch & \\
\hline Spike $t_{s 6}$ & 4 & $\mathrm{C} \rightarrow \mathrm{A}$ Switch & \\
\hline$t_{d 0}$ & 4 & Zero Air reaches the FID & $\begin{array}{c}t_{d 0}-t_{s 6} \text { Residence time in the device } \\
\text { without test pipe }\end{array}$ \\
\hline Spike $t_{s 7}$ & 5 & $\mathrm{~A} \rightarrow \mathrm{B}$ Switch & \\
\hline$t_{u 2}$ & 5 & VOC Mixture entrapped reaches FID & $t_{u 2}-t_{s 7}$ Residence time from $V_{s 2}$ to detector \\
\hline Spike $t_{s 8}$ & 6 & Zero Air reaches FID & $\tau_{R}=t_{s 8}-t_{u 2}$ Residence time in test pipe \\
\hline$t_{d 1}$ & 6 & VOC starts to overpass pipe & Delay of VOC disappearance \\
\hline
\end{tabular}

\subsection{Bias Correction}

The main source of bias comes from the presence of a volume of Zero Air entrapped in the pipe at switch $C \rightarrow D$. The first effect of Zero Air entrapped is to create a depletion in the signal which modifies the integral $(I)$ of dimensionless mole fraction $(\zeta)$ by a quantity that is theoretically equal to the residence time $\left.\left(I=\left(\zeta_{\text {Mix }}-\zeta_{\text {Air }}\right) \tau_{R}=(1-0) \tau_{R}=\tau_{R}\right)\right)$. The effect starts when the air entrapped reaches the FID $\left(t_{d 1}\right)$ and has a duration equal to the residence time $\left(\tau_{R}=t_{s 4}-t_{d 1}\right)$. The second effect is the desorption from the part of the device that connects the test pipe to the detector. This part is saturated by VOC at the $V_{s 2}$ switch time. The effect acts while the air entrapped in the pipe at the $V_{s 2}$ switch time $\left(t_{s 1}\right)$ is crossing that part of the system. The second effect starts to act when the air entrapped reaches the FID $\left(t_{d 1}\right)$, i.e., the $V_{s 2}$ switch time plus the residence time in the part, and has a duration equal to the residence time in the test pipe $\left(\tau_{R}=t_{s 4}-t_{d 1}\right)$. A third effect is the adsorption of the same part of the system that is saturated again while the signal raises up. The third effect starts to act when the gas mixture reaches the FID detector after the $V_{s 2}$ switch $\left(t_{s 4}\right)$ and is persisting till saturation of the part. This results in a bias on the integral, the second and the third effects are equal and opposite.

Thus, the bias can be corrected by subtracting the residence time in the test pipe (first line of Equation (7)) or splitting the integral $(I)$ in desorption $\left(I_{d e s}\right)$ in the interval (from $t_{d 1}$ to 
$\left.t_{s 4}\right)$ and adsorption $\left(I_{a d s}\right)$ in the interval (from $t_{s 4}$ to $t_{\infty}$ ) (second line of Equation (7)). In both intervals, the difference is between the ideal plug flow and the effective signal. During the desorption interval (from $t_{d 1}$ to $t_{s 4}$ ), the gas entrapped in the pipe at $t_{s 1}$ desorbs the VOC from the connection between the test pipe and the detector and modifies the dimensionless mole fraction from the ideal Zero Air $(\zeta=0)$ entrapped to the actual dimensionless mole fraction $(\zeta)$, the integral of the difference $(0-\zeta)$ between the ideal dimensionless mole fraction, and the actual one is the amount of desorption effect in the connection between the test pipe and the detector. While in the adsorption interval (from $t_{s 4}$ to $t_{\infty}$ ), the ideal VOC Mixture plug flow $(\zeta=1)$ is shifted to the actual dimensionless mole fraction $(\zeta)$ because of the adsorption, the integral of the difference $(1-\zeta)$ between the ideal dimensionless mole fraction, and the actual one is the amount of adsorption effect in the test pipe and in the connection between the test pipe and the detector. The sum of the two integrals is the adsorption effect in the test pipe only.

$$
\begin{gathered}
I=\int_{t_{0}}^{t_{\infty}}[1-\zeta(t)] d t-\tau_{r} \\
I=\int_{t_{d 1}}^{t_{44}}[0-\zeta(t)] d t+\int_{t_{s 4}}^{t_{\infty}}[1-\zeta(t)] d t=I_{\text {des }}+I_{\text {ads }}
\end{gathered}
$$

The second approach resulted in much more reproducible and was used in this paper. The measurand equation (Equation (6)) with bias correction becomes:

$$
C_{A, e}=\frac{P^{0}}{R T^{0}} \frac{q_{V_{g}^{0}} \chi_{M i x}}{A}\left(I_{d e s}+I_{a d s}\right)
$$

To make the signals explicit, Equation (8) is transformed in:

$$
C_{A, e}=\frac{P^{0}}{R T^{0}} \frac{q_{V_{g}^{0}} \chi_{M i x}}{A}\left[\int_{t_{d 1}}^{t_{s 4}} \frac{S_{A i r}-S(t)}{S_{M i x}-S_{A i r}} d t+\int_{t_{s 4}}^{t_{\infty}} \frac{S_{M i x}-S(t)}{S_{M i x}-S_{A i r}} d t\right]
$$

The same reasoning can be applied to the desorption section of the experiment to calculate the areic desorbed amount corrected for the bias that comes from the VOC Mixture entrapped in the pipe at switch $A \rightarrow B$ to calculate the measurand. During the adsorption interval (from $t_{u 2}$ to $t_{s 8}$ ), the gas entrapped in the pipe at $t_{s 5}$ adsorbs the VOC to the connection between the test pipe and the detector and modifies the dimensionless mole fraction from the ideal VOC Mixture $(\zeta=1)$ entrapped to the actual dimensionless mole fraction $(\zeta)$, the integral of the difference $(1-\zeta)$ between the ideal dimensionless mole fraction, and the actual one is the amount of adsorption effect in the connection between the test pipe and the detector. While in the desorption interval (from $t_{s 8}$ to $t_{\infty}$ ), the ideal Zero Air plug flow $(\zeta=0)$ is shifted to the actual dimensionless mole fraction $(\zeta)$ because of the desorption, the integral of the difference $(0-\zeta)$ between the ideal dimensionless mole fraction, and the actual one is the amount of desorption effect in the test pipe and in the connection between the test pipe and the detector. The sum of the two integrals is the desorption effect in the test pipe only.

$$
\begin{aligned}
& I=\int_{t_{u 2}}^{t_{s 8}}[1-\zeta(t)] d t+\int_{t_{s 8}}^{t_{\infty}}[0-\zeta(t)] d t+=I_{\text {ads }}+I_{d e s} \\
& C_{A, e}=\frac{P^{0}}{R T^{0}} \frac{q_{V_{g}^{0}} X_{\text {Mix }}}{A}\left[\int_{t_{u 2}}^{t_{s 8}} \frac{S_{\text {Mix }}-S(t)}{S_{\text {Mix }}-S_{\text {Air }}} d t+\int_{t_{s 8}}^{t_{\infty}} \frac{S_{\text {Air }}-S(t)}{S_{\text {Mix }}-S_{\text {Air }}} d t\right]
\end{aligned}
$$

Other possible sources of bias are the interactions with different parts of the system. Valves and pressure reducers are the main sources of uncertainty. Valves have internal surfaces uncoated that can react with Acetone, reducing the accuracy of the method. Pressure reducers have membranes that can release substances that interfere with the detector signal. This paper is aimed to verify the reproducibility of the method. The method is based on the difference between detector response with and without test pipe. It means that the reproducible effects are not interfering with the purpose of the paper because they are canceled by the difference. To assure a higher reproducibility, a single amount fraction has been used to improve the reproducibility of irreversible first-order interactions in the 
valves. The high amount of substance fraction has been selected to reduce the weight of the release from pressure reducers, improving reproducibility. Pressure reducers play an important role when the method is applied at low amount fraction investigation.

\section{Results}

Tests were performed with a sample of Sulfinert ${ }^{\circledR}$ pipe as a whole and cut in 2 subsamples of the same lengths to verify the effects of operating conditions and to verify the reproducibility on samples. Tests were performed at different residence times, flow rates, Reynolds numbers, and temperatures, at atmospheric pressure (plus pressure drop). The ranges of test conditions are reported in Table 3. Tests were repeated on each sample. Data from samples A, B, and C as mean values and mean square deviation of raw data are reported in Table 4.

Table 3. Sulfinert ${ }^{\circledR}$ Number of experiments, pipe lengths, and test condition ranges (residence time, temperature, pressure, and Reynolds number.

\begin{tabular}{|c|c|c|c|c|c|c|c|}
\hline Sample & $\mathbf{N}$ & $\begin{array}{c}L \\
(\mathrm{~m})\end{array}$ & $\begin{array}{c}q_{V_{g}^{0}} \\
\left(\mathrm{SmL} \min ^{-1}\right)\end{array}$ & $\begin{array}{c}\tau_{r} \\
(\min )\end{array}$ & $\begin{array}{c}\mathrm{T} \\
\left({ }^{\circ} \mathrm{C}\right)\end{array}$ & $\begin{array}{c}P \\
(\mathrm{kPa})\end{array}$ & $\begin{array}{l}R e \\
(-)\end{array}$ \\
\hline Sulfinert A & 53 & 26 & 9-195 & $0.5-9.5$ & $22-27$ & 100-130 & $5-150$ \\
\hline Sulfinert B & 29 & 8.5 & $9-55$ & $0.6-3.2$ & $17-30$ & 100-120 & $5-40$ \\
\hline Sulfinert C & 18 & 8.5 & $9-55$ & $0.6-3.2$ & $20-22$ & 100-120 & $5-40$ \\
\hline
\end{tabular}

Data were tested in a range of temperature and pressure due to the room conditions and pressure drop in the device. The three samples are considered as a unique population with respect to temperature and pressure dependency of interaction phenomena as well as the adsorption and the desorption datasets. Welch statistical $t$-tests cannot reject the hypothesis that all data belong to a unique population with a confidence of $95 \%$.

The temperature was calculated as the mean of temperature measured on the external surface of the test pipe along the run time in a different position along the test pipe. A sensitivity coefficient of $2.66 \pm 0.12 \mathrm{nmol} \mathrm{m}^{-2} \mathrm{~K}^{-1}$ was calculated for the temperature (Figure 4) as the slope of the linear regression curve on the whole dataset from the three samples. A different slope was observed for each sample, this is mainly due to the different range of temperature and it is particularly evident in the sample $C$ dataset with a range of temperature of $2 \mathrm{~K}$ against $5 \mathrm{~K}$ for sample $\mathrm{A}$ and $13 \mathrm{~K}$ for sample B. Data were corrected for the temperature bias at $20^{\circ} \mathrm{C}$.

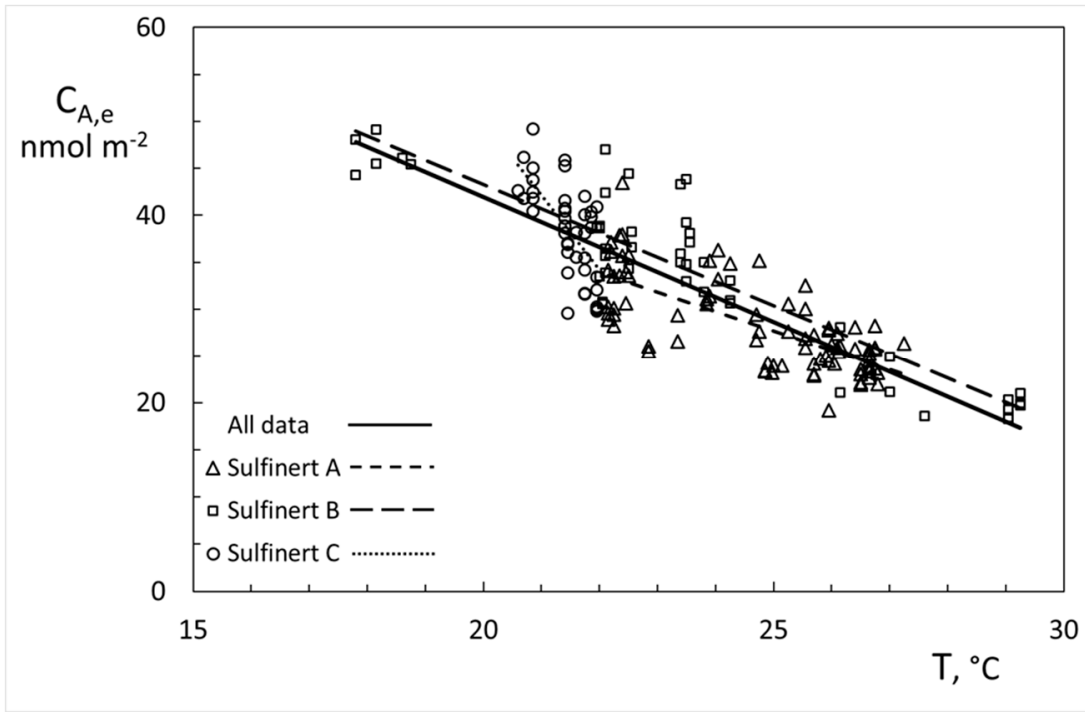

Figure 4. Sensitivity of adsorbed amount per unit area on temperature. 
The pressure was calculated as the mean of maximum and minimum ambient pressure observed during the run added the mean of pressure drop with and without the test pipe, i.e., an estimation of the average pressure along the test pipe. A sensitivity coefficient of $237 \pm 31 \mathrm{nmol} \mathrm{m}^{-2} \mathrm{MPa}^{-1}$ for the pressure (Figure 5) as the slope of the linear regression curve on the whole dataset from the three samples, for data corrected for temperature bias. A different slope was observed for each sample. Data were corrected also for the pressure bias at 1 bar as reported in Table 4 .

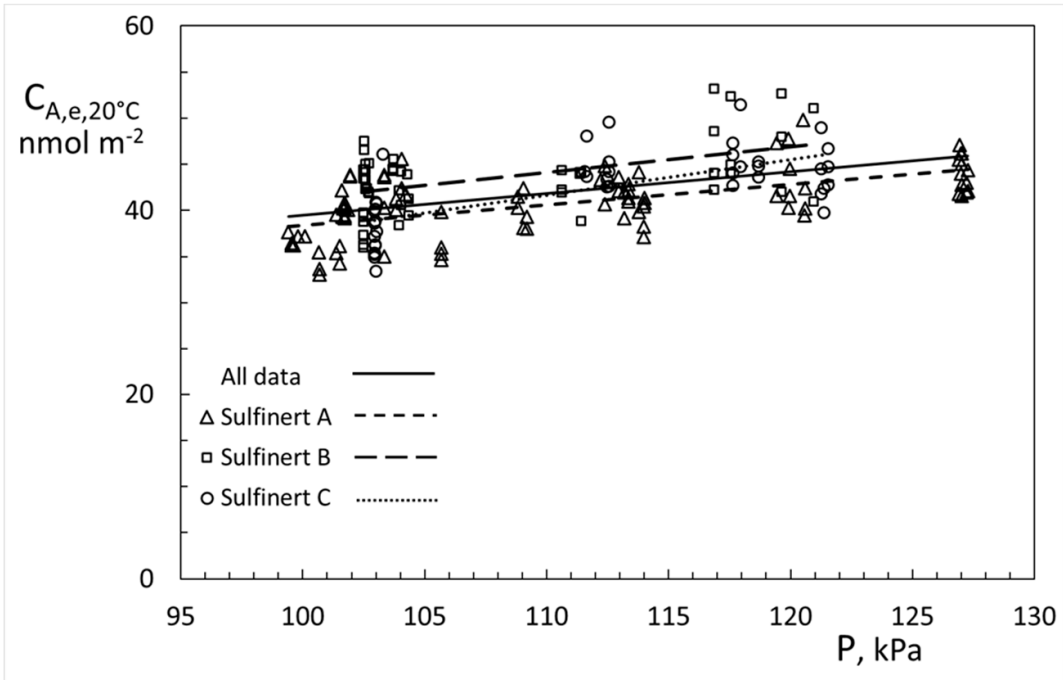

Figure 5. Sensitivity of adsorbed amount per unit area on pressure. The data set was corrected for temperature bias at $20^{\circ} \mathrm{C}$.

Table 4 reports the standard deviation $(\sigma)$ over the datasets including adsorption and desorption values. Lines account for different datasets: single datasets, all the data in one set, and considering samples A, B, and C separately as single data. The variability of data is reduced by the correction of biases depending on the wideness of the temperature and pressure ranges in the specific datasets.

Table 4. Sulfinert ${ }^{\circledR}$ Areic amount adsorbed $\left(C_{A, e}\right)$. Raw data and data corrected at $20{ }^{\circ} \mathrm{C} 1$ bar with experimental standard deviations for a single sample and all data aggregated.

\begin{tabular}{|c|c|c|c|c|c|c|}
\hline Sample & $\begin{array}{c}C_{A, e} \\
\left(\mathrm{nmol} \mathrm{m}^{-2}\right)\end{array}$ & $\begin{array}{c}\sigma \\
\left(\mathrm{nmol} \mathrm{m}^{-2}\right)\end{array}$ & $\begin{array}{c}\sigma \% \\
\sigma / C_{A, e}\end{array}$ & $\begin{array}{l}C_{A, e, 20{ }^{\circ} \mathrm{C}, 1 \mathrm{bar}} \\
\left(\mathrm{nmol} \mathrm{m}^{-2}\right)\end{array}$ & $\begin{array}{l}\sigma, 20^{\circ} \mathrm{C}, 1 \text { bar } \\
\left(\mathrm{nmol} \mathrm{m}^{-2}\right)\end{array}$ & $\begin{array}{c}\sigma_{\% .20^{\circ} \mathrm{C}, 1 \text { bar }} \\
\sigma / \mathrm{C}_{\text {A.e }}\end{array}$ \\
\hline Sulfinert A & 28.2 & 4.8 & $17 \%$ & 38.2 & 2.8 & $7.3 \%$ \\
\hline Sulfinert B & 34.0 & 9.1 & $27 \%$ & 41.7 & 3.3 & $8.0 \%$ \\
\hline Sulfinert C & 38.5 & 4.9 & $13 \%$ & 39.6 & 3.4 & $8.5 \%$ \\
\hline All data & 32.3 & 7.6 & $24 \%$ & 39.5 & 3.4 & $8.6 \%$ \\
\hline Mean ABC & 33.5 & 5.2 & $15 \%$ & 39.8 & 1.7 & $4.4 \%$ \\
\hline
\end{tabular}

Figure 6 shows the plot of average values of the three samples grouped at 6 different Reynolds Number $(R e)$ in order to check a dependency of the adsorbed amount on the fluid dynamic effects inside the pipe. Re was always lower than 200 so a laminar regime always occurred in the test pipes. A slope of $-0.013 \pm 0.006 \mathrm{nmol} \mathrm{m}{ }^{-2}$ was calculated by linear regression on all the data and $-0.018 \pm 0.010 \mathrm{nmol} \mathrm{m}^{-2}$ by linear regression on the mean values, the resulted curves are not plotted in Figure 6 because they are not evidently different from the line of the mean value. The deviation from the mean value was lower than variability on the whole range of $\mathrm{Re}$, and the effect of the slope on the whole range was observed to be lower than the variability of each data subset. Upper and lower lines in Figures 6 and 7 are the envelopes of all data, max and minimum values have an opposite trend against Re. In conclusion, Re does not affect the amount of Acetone adsorbed per unit area of the pipe wall. 
Figure 7 show the plot of average values of the three samples grouped at 5 different residence time in order to check a dependency of the adsorbed amount on the contact time. Contact time ranged between 0.5 and $9 \mathrm{~min}$ for all the samples. A slope of $-0.46 \pm 0.12 \mathrm{nmol} \mathrm{m}^{-2} \mathrm{~min}^{-1}$ was calculated by linear regression on all the data and $-0.57 \pm 0.13 \mathrm{nmol} \mathrm{m}^{-2} \mathrm{~min}^{-1}$ by linear regression on the mean values. The variability of the mean values seems lower for residence time lower than $4 \mathrm{~min}$. The upper and lower lines in Figure 7 are the envelope of all data, minimum values have a flat trend against the residence time. The effect of residence time on the adsorbed amount per unit area is not completely clear but, in any case, very limited.

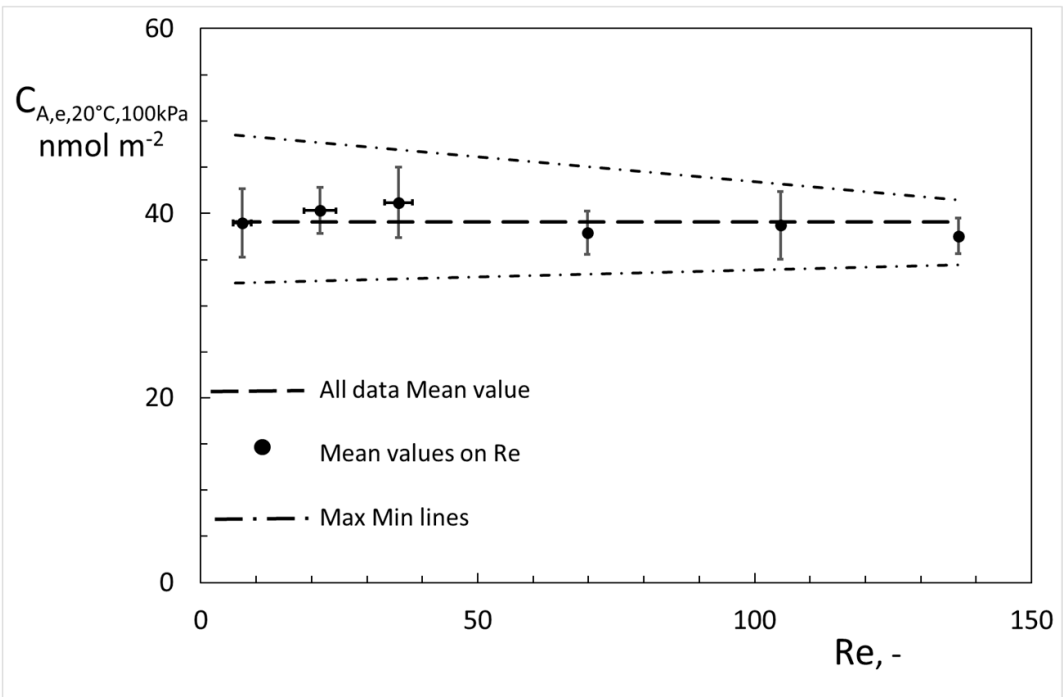

Figure 6. Sensitivity of adsorbed amount per unit area on Reynolds number. Values corrected at $20^{\circ} \mathrm{C}, 1$ bar, and grouped on $R e$.

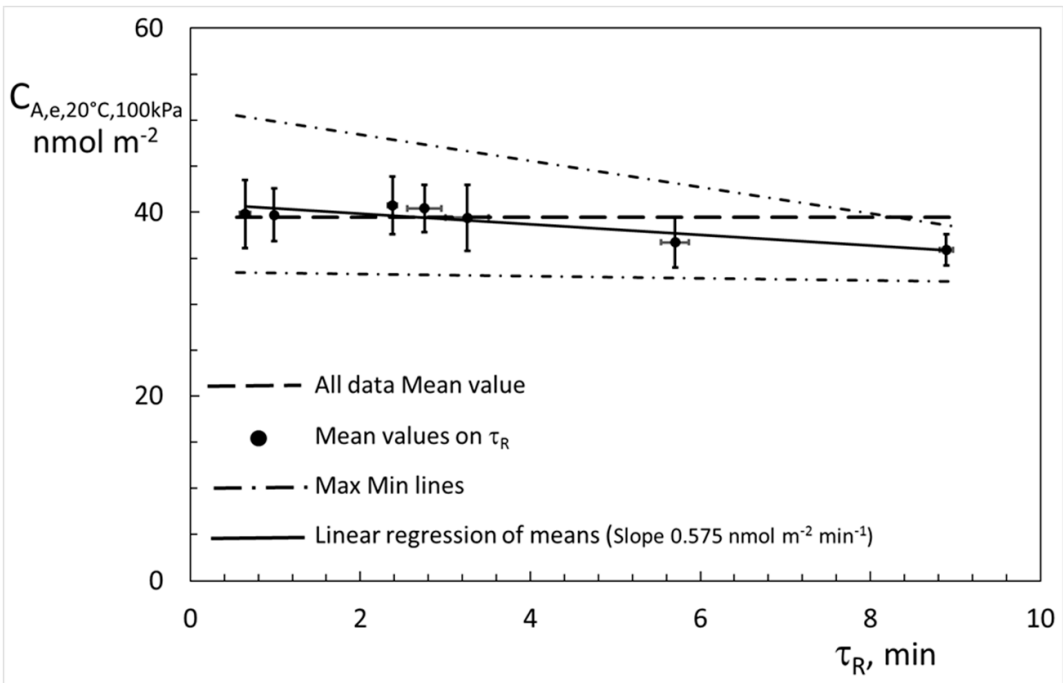

Figure 7. Sensitivity of adsorbed amount per unit area on residence time. Values corrected at $20^{\circ} \mathrm{C}$, 1 bar and grouped on $\tau_{R}$.

The longer sample, sample A, was the only one working at a high Reynolds number (more than 50) and at a high residence time (more than $4 \mathrm{~min}$ ). Both in Figures 6 and 7 a lower value is observed, much more evident in Figure 7 . Since the average value of sample A is lower (Table 4), the effect of the sample could be the only relevant on differences.

The comparison of adsorption and desorption runs allows analyzing the reversibility of the interactions. The difference between the amounts of Acetone that disappeared in 
the first part of the run and appeared in the second part of the run was calculated to be $1.5 \pm 0.33 \mathrm{nmol} \mathrm{m}^{-2}$ as the difference of the mean values corrected for the temperature and pressure biases and $2.3 \pm 0.53 \mathrm{nmol} \mathrm{m}^{-2}$ as the mean of the differences measured in each run. Reproducibility was calculated as the standard deviation of the mean.

\section{Discussion}

The measurand was defined and realized by the mass balance of VOC across the test pipe. An experimental device was specially designed to improve the reproducibility of experiments in data production even without a narrow control of temperature and pressure. The flow rate was kept under control by sonic nozzles and inlet pressure regulation as mass flow rate, volumetric flow rates, and pressures were kept reproducible regulating pressure drops by capillary pipes in both vent and detector lines. Four-way switch crossover valves were used to reduce the area of bypass and to make switches by a unique movement to change from zero gas to the VOC mixtures (Acetone) and to insert and from bypass to the test pipe. Biases were corrected accounting for desorption in the line that connects the test pipe to the detector.

The extent of the range of temperature, mainly due to the seasonal variations, was around $10 \mathrm{~K}$ and a correction was necessary to compare data, a sensitivity factor on temperature was calculated. The extent of the range of pressure, mainly due to the pressure drop under different operational conditions, was around $30 \mathrm{kPa}$ and a correction was necessary to compare data, a sensitivity factor on pressure was calculated.

Table 5 reports mean values and standard deviation of the mean for single datasets, for all the data in one set and considering samples A B and C separately as single data in order to compare the reproducibility of the method and to focus on the difference between samples. The standard deviation of the mean of the dataset with data corrected for temperature and pressure is considered as the total uncertainty of the measurement [53]. The value is very small around 1\%, this could mainly due to the characteristic of Sulfinert ${ }^{\circledR}$ coating on stainless steel that assures very low irreversible interferences and no permeation into the pipe wall limiting the instability of measurand. A poorer reproducibility is expected with polymeric materials or uncoated metals. This result candidate the method for quality control of the coating by a reference procedure.

Table 5. Sulfinert ${ }^{\circledR}$ specific amount adsorbed $\left(C_{A, e}\right)$ and equilibrium constant $\left(K_{e}\right)$. Data were corrected at $20^{\circ} \mathrm{C} 1$ bar. Reproducibility as the experimental standard deviation of the mean of corrected data. Single Sulfinert ${ }^{\circledR}$ samples A, B, C, all data sets in one and calculated from the samples.

\begin{tabular}{|c|c|c|c|c|c|c|}
\hline Sample & $\begin{array}{l}C_{A, e, 20}{ }^{\circ} \mathrm{C}, 1 \mathrm{bar} \\
\left(\mathrm{nmol} \mathrm{m}^{-2}\right)\end{array}$ & $\begin{array}{c}\sigma_{20^{\circ} \mathrm{C}, 1 \mathrm{bar}} \\
\left(\mathrm{nmol} \mathrm{m}^{-2}\right)\end{array}$ & $\begin{array}{c}\sigma_{\%, 20}{ }^{\circ} \mathrm{C}, 1 \text { bar } \\
\sigma / C_{A, e}\end{array}$ & $\begin{array}{c}K_{e, 20}{ }^{\circ} \mathrm{C}, 1 \mathrm{bar} \\
\text { (m) }\end{array}$ & $\begin{array}{c}\sigma_{, 20}{ }^{\circ} \mathrm{C}, 1 \text { bar } \\
(\mathrm{m})\end{array}$ & $\begin{array}{c}\sigma_{\%, 20}{ }^{\circ} \mathrm{C}, 1 \text { bar } \\
\sigma / K_{e}\end{array}$ \\
\hline Sulfinert A & 38.2 & 0.3 & $0.8 \%$ & 0.173 & 0.002 & $1.0 \%$ \\
\hline Sulfinert B & 41.7 & 0.5 & $1.2 \%$ & 0.185 & 0.003 & $1.5 \%$ \\
\hline Sulfinert C & 39.6 & 0.5 & $1.3 \%$ & 0.171 & 0.002 & $1.4 \%$ \\
\hline All data & 39.5 & 0.3 & $0.7 \%$ & 0.176 & 0.001 & $0.8 \%$ \\
\hline Mean ABC & 39.8 & 1.0 & $2.5 \%$ & 0.176 & 0.005 & $2.6 \%$ \\
\hline
\end{tabular}

The same reproducibility among samples $1.00 \mathrm{nmol} \mathrm{m}^{-2}$ was calculated as uniform distribution of probability between the maximum and minimum observed values, and as the normal distribution of probability, i.e., the standard deviation of the mean of the three values. Reproducibility between samples is around $2.5 \%$ of the value calculated as Type A uncertainty [53].

If a linear equation is used to describe the equilibrium condition between a VOC mixture and the pipe internal surface, the equilibrium constant can be calculated as the ratio between the areic mole of $\operatorname{VOC}\left(C_{A, e}\right)$ on the wall surface and the mole concentration in the gas mixture at the equilibrium $\left(C_{V, e}\right)[30]$ :

$$
K_{e}=\frac{C_{A, e}}{C_{V, e}}
$$


The measured values are reported in the last columns of Table 5. As expected, the constant does not depend on the fluid dynamic conditions $(R e)$ and on the contact time between the VOC Mixture and the pipe, the constant value depends on temperature and pressure.

\section{Conclusions}

Uncertainty of VOC measurements at ppb level is affected by the interactions of gas mixtures with the sampling lines especially when concentration is at trace levels. A key topic is the quantification of the loss amount that can be considered as a bias for the measurement of the amount of VOC. The method here proposed is an experimental quantification of interactions that reaches an equilibrium between a gas mixture and a pipe wall. Even if the actual quantification is at ppm level, due to the available VOC mixture source and the available detector, the method is applicable in principle to lower concentration levels depending on the availability of a mixture source and a detector. The ppm level assures a good reproducibility and has insights to lower levels if the interaction mechanisms remain the same as expected.

The device allowed to have good control of the experiment. The 4-way valves are really effective in switches giving a limited disturbance on pressure and signal and minimize the surface area in the bypass. Sonic nozzles allowed good stability to the flow rates being independent of the discharge pressure. The control of temperature and pressure was not critical, even if it was really very broad. The estimation of average temperature and pressure inside the test pipe was effective for the calculation of the biases. The method can be applied to compare different materials or scenarios, or to investigate competition between substances, e.g., with moisture. In the last case, the mutual effects of substances on detectors and mixture generators can be critical. The method is actually under investigation at a very low level of amount of substance ( $\mathrm{ppb}$ ) with a PTR-MS as a detector, with acetone, methanol, and ethanol as VOCs and at different levels of moisture.

Author Contributions: Conceptualization, G.S. and M.L.; methodology, G.S.; software, B.A.K.; validation, G.S.; formal analysis, G.S. and M.L.; investigation, B.A.K.; resources, G.S.; data curation, B.A.K.; writing-original draft preparation, G.S. and B.A.K.; writing-review and editing, G.S. and M.L.; supervision, G.S.; funding acquisition, G.S. and M.L. All authors have read and agreed to the published version of the manuscript.

Funding: This work was supported by EMPIR funds on 19ENV06, MetClimVOC project. The European Metrology Program For Innovation And Research (EMPIR) is jointly funded by the EMPIR participating countries within EURAMET and the European Union.

Institutional Review Board Statement: Not applicable.

Informed Consent Statement: Not applicable.

Data Availability Statement: The data presented in this study are available on request from the corresponding author. The data are not publicly available due to privacy.

Conflicts of Interest: The authors declare no conflict of interest.

\section{References}

1. Sassi, G.; Demichelis, A.; Lecuna, M.; Sassi, M.P. Preparation of standard VOC mixtures for climate monitoring. Int. J. Environ. Anal. Chem. 2015, 95, 1195-1207. [CrossRef]

2. Investigations for the Improvement of the Measurement of Volatile Organic Compounds from Floor Coverings within the HealthRelated Evaluation of Construction Products. Available online: https: / www.google.com.sg/url?sa=t\&rct=j\&q=\&esrc=s\&source= web\&cd=\&cad=rja\&uact=8\&ved=2ahUKEwj7wPb9wujuAhW5yYsBHSoFD_kQFjABegQIBBAC\&url=https\%3A\%2F\%2Fopus4

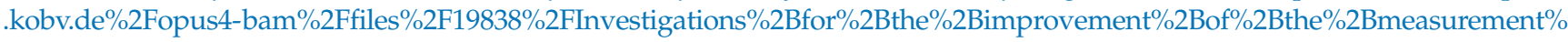

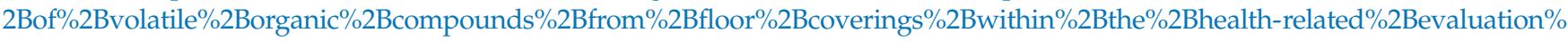
2Bof\%2Bconstruction\%2Bproducts.pdf\&usg=AOvVaw2zTZtBrY2SQkxJekU3Qu9r (accessed on 27 January 2021).

3. Penkett, S. GAW Report No. 171: A WMO/GAW Expert Workshop on Global Long-Term Measurements of Volatile Organic Compounds (VOCs); World Meteorological Organization (WMO): Geneva, Switzerland, 2007.

4. Rappengluck, B.; Apel, E.; Bauerfeind, M.; Bottenheim, J.; Brickell, P.; Cavolka, P.; Cech, J.; Gatti, L.; Hakola, H.; Honzak, J.; et al. The first VOC intercomparison exercise within the Global Atmosphere Watch (GAW). Atmos. Env. 2006, 20, 7508-7527. [CrossRef] 
5. Pascale, C. 19ENV06, MetClimVOC, Metrology for Climate Relevantvolatile Organic Compounds. European Metrology Programme for Innovation AndResearch (EMPIR). 2019. Available online: https://www.aramis-r.admin.ch/Kategorien/?ProjectID= 47398\&Sprache=en-US (accessed on 27 January 2021).

6. Roberts, M.; Reiss, M.; Monger, G. Advanced Biology; Nelson Thornes: Cheltenham, UK, 2000.

7. Rovelli, S.; Cattaneo, A.; Fazio, A.; Spinazzè, A.; Borghi, F.; Campagnolo, D.; Dossi, C.; Cavallo, D.M. VOCs Measurements in Residential Buildings: Quantification via Thermal Desorption and Assessment of Indoor Concentrations in a Case-Study. Atmosphere 2019, 10, 57. [CrossRef]

8. De Gennaro, G.; Farella, G.; Marzocca, A.; Mazzone, A.; Tutino, M. Indoor and outdoor monitoring of volatile organic compounds in school buildings: Indicators based on health risk assessment to single out critical issues. Int. J. Environ. Res. Public Health 2013, 10, 6273-6291. [CrossRef] [PubMed]

9. Adgate, J.; Church, T.; Ryan, A.; Ramachandran, G.; Fredrickson, A.; Stock, T.; Morandi, M.; Sexton, K. Outdoor, indoor, and personal exposure to VOCs in children. Environ. Health Perspect. 2004, 112, 1386-1392. [CrossRef] [PubMed]

10. Demichelis, A.; Sassi, G.; Lecuna, M.; Sassi, M. Molar fraction stability in dynamic preparation of reference trace gas mixtures. IET Sci. Meas. Technol. 2016, 10, 414-419. [CrossRef]

11. Vogt, S.R.; Landoni, C. Approaches to airborne molecular contamination assessment. In Metrology, Inspection, and Process Control for Microlithography XXV; SPIE: Washington, DC, USA, 2011.

12. Hattori, T. Chemical Contamination Control in ULSI Wafer Processing. 2001. Available online: https://aip.scitation.org/doi/ pdf/10.1063/1.1354411 (accessed on 27 January 2021).

13. Gordon, S.M.; Szidon, J.P.; Krotoszynski, B.K.; Gibbons, R.D.; O’Neill, H.J. Volatile organic compounds in exhaled air from patients with lung cancer. Clin. Chem. 1985, 31, 1278-1282. [CrossRef] [PubMed]

14. Peng, G.; Tisch, U.; Adams, O.; Hakim, M.; Shehada, N.; Broza, Y.Y.; Billan, S.; Abdah-Bortnyak, R.; Kuten, A.; Haick, H. Diagnosing lung cancer in exhaled breath using gold nanoparticles. Nat. Nanotechnol. 2009, 4, 669-673. [CrossRef] [PubMed]

15. Wang, C.; Dong, R.; Wang, X.; Lian, A.; Chi, C.; Ke, C.; Guo, L.; Liu, S.; Zhao, W.; Xu, G. Exhaled volatile organic 16ompound sas lung cancer biomarkers during one-lung ventilation. Sci. Rep. 2014, 4, 1-8.

16. Adiguzel, Y.; Kulah, H. Breath sensors for lung cancer diagnosis. Biosens. Bioelectron. 2015, 65, 121-138. [CrossRef] [PubMed]

17. Daneshkhah, A.; Siegel, A.P.; Agarwal, M. Volatile organic compounds: Potential biomarkers for improved diagnosis and monitoring of diabetic wounds. In Wound Healing, Tissue Repair, and Regeneration in Diabetes; Elsevier: Amsterdam, The Netherlands, 2020; pp. 491-512.

18. Rhoderick, G.C.; Cecelski, C.E.; Miller, W.R.; Worton, D.R.; Moreno, S.; Brewer, P.J.; Viallon, J.; Idrees, F.; Moussay, P.; Kim, Y.D.; et al. Stability of gaseous volatile organic compounds contained in gas cylinders with different internal wall treatments. Elementa 2019, 7, 28. [CrossRef]

19. Brewer, P.; Brown, R.; Mussell, E.; van Aswegen, S.; Ward, M.; Hill-Pearce, R.; Worton, D. Breakthrough in Negating the Impact of Adsorption in Gas Reference Materials. Anal. Chem. 2019, 91, 5310-5315. [CrossRef]

20. Pagonis, D.; Krechmer, J.E.; De Gouw, J.; Jimenez, J.L.; Ziemann, P.J. Effects of gas-wall partitioning in Teflon tubing and instrumentation on time-resolved measurements of gas-phase organic compounds. Atmos. Meas. Tech. 2017, 10, 4687-4696. [CrossRef]

21. Yeh, G.K.; Ziemann, P.J. Gas-wall partitioning of oxygenated organic compounds: Measurements, structure-activity relationships, and correlation with gas chromatographic retention factor. Aerosol Sci. Tech. 2015, 49, 727-738. [CrossRef]

22. Krechmer, J.E.; Pagonis, D.; Ziemann, P.J.; Jimenez, J.L. Quantification of gas-wall partitioning in Teflon environmental chambers using rapid bursts of low-volatility oxidized species generated in situ. Environ. Sci. Tech. 2016, 50, 5757-5765. [CrossRef] [PubMed]

23. Ye, P.; Ding, X.; Hakala, J.; Hofbauer, V.; Robinson, E.S.; Donahue, N.M. Vapor wall loss of semi-volatile organic compounds in a Teflon chamber. Aerosol Sci. Tech. 2016, 50, 822-834. [CrossRef]

24. Huang, Y.; Zhao, R.; Charan, S.M.; Kenseth, C.M.; Zhang, X.; Seinfeld, J.H. Unified Theory of Vapor-Wall Mass Transport in Teflon-Walled Environmental Chambers. Environ. Sci. Tech. 2018, 52, 2134-2142. [CrossRef]

25. Arrhenius, K.; Fischer, A.; Büker, O. Methods for sampling biogas and biomethane on adsorbent pipes after collection in gas bags. Appl. Sci. 2019, 9, 1171. [CrossRef]

26. Liu, X.; Deming, B.; Pagonis, D.; Day, D.A.; Palm, B.B.; Talukdar, R.; Roberts, J.M.; Veres, P.R.; Krechmer, J.E.; Thornton, J.A.; et al. Effects of gas-wall interactions on measurements of semivolatile compounds and small polar molecules. Atmos. Meas. Tech. 2019, 12,3137-3149. [CrossRef]

27. McMurry, P.H.; Grosjean, D. Gas and aerosol wall losses in Teflon film smog chambers. Environ. Sci. Tech. 1985, 19, 1176-1182. [CrossRef]

28. McCabe, W.; Smith, J.; Harriott, P. Unit Operations of Chemical Engineering; McGraw Hill: New York, NY, USA, 1956.

29. Zhang, J.; Zhang, J.; Chen, Q.; Yang, X. A critical review on studies of volatile organic compound (VOC) sorption by building materials (RP-1097). Trans. Am. Soc. Heat. Refriger. Air Cond. Eng. 2001, 108, 162-174.

30. Goss, K.-U. The air/surface adsorption equilibrium of organic compounds under ambient conditions. Crit. Rev. Environ. Sci. Tech. 2004, 34, 339-389. [CrossRef] 
31. Metrology for VOC Indicators in Air Pollution and Climate Change. Euramet European Metrology Research Programme (EMRP). 2013. Available online: https:/ / www.era-learn.eu/network-information/networks/emrp/emrp-call-2013-energy-andenvironment/metrology-for-voc-indicators-in-air-pollution-and-climate-change (accessed on 27 January 2021).

32. Nowak, J.; Neuman, J.; Kozai, K.; Huey, L.; Tanner, D.; Holloway, J.; Ryerson, T.; Frost, G.; McKeen, S.; Fehsenfeld, F. A chemical ionization mass spectrometry technique for airborne measurements of ammonia. J. Geophys. Res Atmos. 2007, 112, D10. [CrossRef]

33. Neuman, J.A.; Huey, L.G.; Ryerson, T.B.; Fahey, D.W. Study of inlet materials for sampling atmospheric nitric acid. Environ. Sci. Tech. 1999, 33, 1133-1136. [CrossRef]

34. World Meteorological Organization (WMO). Standard Operating Procedures (SOPs) for Air Sampling in Stainless Steel Canisters for Non-Methane. 2012. Available online: https:/ /library.wmo.int/index.php?lvl=notice_display\&id=13702\#.YCjHezLiuUk (accessed on 27 January 2021).

35. Ma, C.; Haider, A.M.; Shadman, F. Atmospheric pressure ionization mass spectroscopy for the study of permeation in polymeric tubing. IEEE Trans. Semicond. Manuf. 1993, 6, 361-366. [CrossRef]

36. Matsunaga, A.; Ziemann, P.J. Gas-wall partitioning of organic compounds in a Teflon film chamber and potential effects on reaction product and aerosol yield measurements. Aerosol Sci. Tech. 2010, 44, 881-892. [CrossRef]

37. Lee, S.; Kim, M.E.; Oh, S.H.; Kim, J.S. Determination of physical adsorption loss of primary standard gas mixtures in cylinders using cylinder-to-cylinder division. Metrologia 2017, 54, L26. [CrossRef]

38. Langmuir, I. The adsorption of gases on plane surfaces of glass, mica and platinum. J. Am. Chem. Soc. 1918, 40, 1361-1403. [CrossRef]

39. Sassi, G.; Demichelis, A.; Sassi, M.P. Uncertainty analysis of the diffusion rate in the dynamic generation of volatile organic compound mixtures. Meas. Sci. Tech. 2011, 22, 105104. [CrossRef]

40. Takahashi, C.; Kato, K.; Maruyama, M.; Kim, J.S.; Kao, M.-J.; Botha, A.; Dimashki, M. Final report on key comparison APMP. QM-K4 of ethanol in air. Metrologia 2003, 40, 08008. [CrossRef]

41. Kato, K.; Maruyama, M.; Kim, J.S.; Hyub, O.S.; Woo, J.-C.; Kim, Y.; Bae, H.; Han, Q.; Zhou, Z. Final report on key comparison APMP. QM-K4. 1: Ethanol in nitrogen. Metrologia 2007, 45, 08007. [CrossRef]

42. Guenther, F.R.; Miller, W.R.; Duewer, D.L.; Heo, G.S.; Kim, Y.-D.; van der Veen, A.M.H.; Konopelko, L.; Kustikov, Y.; Shor, N.; Brookes, C.; et al. International Comparison CCQM-K41: Hydrogen sulfide in nitrogen. Metrologia 2007, 44, 08004. [CrossRef]

43. Kim, Y.-D.; Heo, G.-S.; Lee, S.; Han, Q.; Wu, H.; Konopelko, L.A.; Kustikov, Y.A.; Malginov, A.V.; Gromova, E.V.; Pankratov, V.V.; et al. Final report on international key comparison APMP. QM-K41: $10 \mu \mathrm{mol} / \mathrm{mol}$ hydrogen sulfide in nitrogen. Metrologia 2014, 51, 08012. [CrossRef]

44. Van der Veen, M.H.; Nieuwenkamp, G.; Wessel, R.M.; Maruyama, M.; Heo, G.S.; Kim, Y.-D.; Moon, D.M.; Niederhauser, B.; Quintilii, M.; Milton, M.J.T.; et al. International comparison CCQM K46-Ammonia in nitrogen. Metrologia 2010, 47, 08023. [CrossRef]

45. Brown, A.S.; Milton, M.; Brookes, C.; Vargha, G.; Downey, M.; Uehara, S.; Augusto, C.; de Lima Fioravante, A.; Sobrinho, D.; Dias, F.; et al. Final report on CCQM-K93: Preparative comparison of ethanol in nitrogen. Metrologia 2013, 50, 08025. [CrossRef]

46. Lee, S.; Heo, G.S.; Kim, Y.; Oh, S.; Han, Q.; Wu, H.; Konopelko, L.A.; Kustikov, Y.A.; Kolobova, A.V.; Efremova, O.V.; et al. International key comparison CCQM-K94: $10 \mu \mathrm{mol} / \mathrm{mol}$ dimethyl sulfide in nitrogen. Metrologia 2016, 53, 08002. [CrossRef]

47. Harris, P.; Pelligrini, M. Mass Transport in Sample Transport lines Adsorption Desorption Effects and their Influence on Process Analytical Measurements. Available online: https:/ /www.silcotek.com/hubfs/Literature\%20Catalog/White\%20Papers/ Externally \%20Written/Sulfur\%20and\%20H2S/\%23WP-EXT-SULF-002\%20ISA\%202011\%20Sample\%20Lines.pdf (accessed on 27 January 2021).

48. Deming, L.; Pagonis, D.; Liu, X.; Day, D.A.; Talukdar, R.; Krechmer, J.E.; de Gouw, J.A.; Jimenez, J.L.; Ziemann, P.J. Measurements of delays of gas-phase compounds in a wide variety of tubing materials due to gas-wall interactions. Atmos. Meas. Tech. 2019, 12, 3453-3461. [CrossRef]

49. Metrology for Airborne Molecular Contamination in Manufacturing Environments. European Metrology Research Programme (EMRP). 2012. Available online: https: / / www.euramet.org/index.php?eID=tx_securedownloads\&p=588\&u=0\&g=0\&t=16415281 79\&hash=31fb1f3ab963204de5ce80ba65fc8605b53c7edf\&file=Media /docs /EMRP/JRP/JRP_Summaries_2012/Industry_SRTs / SRT-i17.pdf (accessed on 27 January 2021).

50. Barwood, G. 17IND09, MetAMCII, Metrology for Airborne Molecular Contaminants II European. Metrology Programme for Innovation and Research (EMPIR). 2017. Available online: https://www.era-learn.eu/network-information/networks/empir/ empir-call-2017/metrology-for-airborne-molecular-contaminants-ii (accessed on 27 January 2021).

51. Szulejko, J.; Kim, Y.H.; Kim, K.H. Method to predict gas chromatographic response factors for the trace-level analysis of volatile organic compounds based on the effective carbon number concepts. J. Sep. Sci. 2013, 36, 3356-3365. [CrossRef]

52. University of Torino. Meteorological Station of the Department of Physics. 2020. Available online: http:/ / www.meteo.dfg.unito. it/tutti (accessed on 27 January 2021).

53. Evaluation of Measurement Data-Guide to the Expression of Uncertainty in Measurement (GUM) JCGM 100:2008. Available online: https://www.bipm.org/utils/common/documents/jcgm/JCGM_100_2008_E.pdf (accessed on 27 January 2021). 